\title{
Impact of virtual reality simulation on learning barriers of phacoemulsification perceived by residents
}

This article was published in the following Dove Press journal:

Clinical Ophthalmology

\author{
Danny Siu-Chun $\mathrm{Ng}^{\prime}$ \\ Zihan Sun'
}

Alvin Lerrmann Young ${ }^{1,2}$

Simon Tak-Chuen $\mathrm{Ko}^{3}$

Jerry Ka-Hing Lok'

Timothy Yuk-Yau Lai'

Shameema Sikder ${ }^{4}$

Clement C Tham'

'Department of Ophthalmology and Visual Sciences, The Chinese

University of Hong Kong,

2Department of Ophthalmology,

Prince of Wales Hospital,

${ }^{3}$ Department of Ophthalmology,

Tung Wah Eastern Hospital, Hong

Kong, People's Republic of China;

${ }^{4}$ Wilmer Eye Institute, Johns Hopkins

University, Baltimore, MD, USA
Correspondence: Clement C Tham Department of Ophthalmology and Visual Sciences, The Chinese University of Hong Kong, 4/F Hong Kong Eye Hospital, I47K Argyle Street, Mongkok, Hong Kong,

People's Republic of China

Tel +85239435858

Fax +852 27I59490

Email clemtham@cuhk.edu.hk
Objective: To identify residents' perceived barriers to learning phacoemulsification surgical procedures and to evaluate whether virtual reality simulation training changed these perceptions. Design: The ophthalmology residents undertook a simulation phacoemulsification course and proficiency assessment on the Eyesi system using the previously validated training modules of intracapsular navigation, anti-tremor, capsulorrhexis, and cracking/chopping. A cross-sectional, multicenter survey on the perceived difficulties in performing phacoemulsification tasks on patients, based on the validated International Council of Ophthalmology's Ophthalmology Surgical Competency Assessment Rubric (ICO-OSCAR), using a 5-point Likert scale (1 = least and $5=$ most difficulty), was conducted among residents with or without prior simulation training. Mann-Whitney $U$ tests were carried out to compare the mean scores, and multivariate regression analyses were performed to evaluate the association of lower scores with the following potential predictors: 1) higher level trainee, 2) can complete phacoemulsification most of the time ( $>90 \%)$ without supervisor's intervention, and 3) prior simulation training.

Setting: The study was conducted in ophthalmology residency training programs in five regional hospitals in Hong Kong.

Results: Of the 22 residents, 19 responded (86.3\%), of which 13 (68.4\%) had completed simulation training. Nucleus cracking/chopping was ranked highest in difficulty by all respondents followed by capsulorrhexis completion and nucleus rotation/manipulation. Respondents with prior simulation training had significantly lower difficulty scores on these three tasks (nucleus cracking/chopping 3.85 vs $4.75, P=0.03$; capsulorrhexis completion 3.31 vs $4.40, P=0.02$; and nucleus rotation/manipulation 3.00 vs $4.75, P=0.01$ ). In multivariate analyses, simulation training was significantly associated with lower difficulty scores on these three tasks.

Conclusion: Residents who had completed Eyesi simulation training had higher confidence in performing the most difficult tasks perceived during phacoemulsification.

Keywords: virtual reality, simulation surgical education, cataract surgery

\section{Introduction}

The global number of blindness due to cataract has increased from 12.3 million in 1990 to 20 million in 2010. ${ }^{1,2}$ In East Asia, including Hong Kong, cataract is the leading cause of blindness and visual impairment in the pooled data of population-based studies. ${ }^{3,4}$ Various initiatives have been undertaken in response to fight the cataract epidemic in Hong Kong, including implementation of key performance indicator based on the waiting time for cataract surgery in public hospitals and subsidization for cataract surgery in public-private partnership programs. As a result, the average waiting time for cataract surgery in public hospitals has markedly reduced approximately threefold, 
from over 44 months before 2008 to 15 months after $2013 .^{5}$ As physicians have pledged to keep shortening the waiting time, the demand for cataract surgeries will continue to be relentless.

Alongside the rising demand for cataract surgeries, there is a constant influx of ophthalmic residents. Learning to competently perform phacoemulsification is one of their top training priorities. Traditionally, residents learned phacoemulsification based on the Halsted apprenticeship model, ${ }^{6}$ in which they perform the techniques step by step on actual patients under the close supervision of an attending physician. A wide range of intraoperative complication rates from $2.0 \%$ to $14.7 \%$ in resident-performed phacoemulsification surgeries have been reported; while some phacoemulsification surgeries performed by residents have comparable outcomes, ${ }^{7-9}$ others have increased complication rates and worse patient outcomes. ${ }^{10-16}$ The highly variable complication rates could be due to the lack of systematic consideration of potential perioperative risk factors, such as history of traumatic cataracts, hypermature cataracts, and zonular loosening. ${ }^{10}$ Nonetheless, the cost of training during live surgeries may be higher due to prolonged operation time. ${ }^{17,18}$ With rising patient expectations and demands of high-quality surgical outcomes, it is vital that ophthalmic residents learn to operate in a manner that is safe and time efficient.

A pilot virtual reality simulation cataract surgery training course was conducted in Hong Kong using the validated training modules on the Eyesi (VRmagic, Holding AG, Mannheim, Germany) computer-generated three-dimensional cataract operation environment for ophthalmic residents. A cross-sectional survey was conducted after the course for participants and nonparticipants of the course. The objectives of this study were to identify the residents' perceived barriers to learning phacoemulsification procedures and whether simulation training on Eyesi changed these perceptions.

\section{Methods}

\section{Simulation training curriculum}

A structured, certified phacoemulsification simulation training course was held for ophthalmic residents who participated on a voluntary basis at The Chinese University of Hong Kong Ophthalmic Microsurgical Training Centre, the only virtual reality eye surgery simulation training facility in Hong Kong. The course included didactic lectures and hands-on practicum on the Eyesi simulator. Before simulation training began, all participants were given a 2-hour formal introduction and standardized instructions on how to use the Eyesi phacoemulsification interface software version 2.8 by the training coordinator. Four training modules with specific difficulty levels were chosen because their construct validities had been demonstrated previously. ${ }^{19-24}$ The modules consisted of a mix of generic three-dimensional and cataract-specific, static and dynamic tasks in order to capture a full range of dexterity and skill as measured and trained by the simulator. Three of them were single-handed tasks (cataract navigation training [intracapsular], level 3; cataract anti-tremor training [intracapsular], level 2; capsulorrhexis training, level 1), and one was a bimanual task (cataract cracking and chopping training, level 2). The participants were given as much practice time as possible before sitting in for a test at the end of the 4-week course. For each of the four tasks, participants could achieve a maximum score of 100 , resulting in a total maximum course score of 400 . A proficiency test was performed under supervision, which required $80 \%$ passing mark. A certificate was awarded upon successful completion of the course.

\section{Survey}

A cross-sectional, anonymous, self-administered territorywide survey of ophthalmic residents' self-perceived learning barriers to phacoemulsification techniques, based on modifications of the validated International Council of Ophthalmology's Ophthalmology Surgical Competency Assessment Rubric (ICO-OSCAR) - Phacoemulsification tool, ${ }^{25}$ was conducted among ophthalmic residents in Hong Kong regardless of their participation in the simulation training course or not (Figure 1). The study adhered to the tenets of the Declaration of Helsinki. Informed consent was signed by all subjects. The study was approved by the Hong Kong hospital authority cluster institutional review board. The residents were affiliated with five regional hospitals throughout the three major districts in Hong Kong: Tung Wah Eastern Hospital and Pamela Youde Nethersole Eastern Hospital in Hong Kong Island, Hong Kong Eye Hospital in Kowloon, Alice Ho Miu Ling Nethersole Hospital, and Prince of Wales Hospital in the New Territories. The coverage was about $50 \%$ of all ophthalmic resident doctors throughout the Hong Kong Special Administrative Region. After reading the specific guidelines for grading of each surgical step listed on the ICO-OSCAR, the respondents ranked the levels of perceived difficulty on a 5 -point scale $(1=$ least and $5=$ most difficult) for each of the 14 phacoemulsification procedures and six global indices on the survey. In addition, they provided demographic information, and answered questions on their training status (basic or higher ophthalmic trainees, as determined by whether they had passed the intermediate 
Please CIRCLE one of the following:

1. Number of years of training as ophthalmic resident?

2. Training status:

3. Can you complete phacoemulsification cataract extraction surgery in patients

Basic Trainee

No Yes

most of the time $(>90 \%)$ without any intervention from your supervisors?

4. Eyesi phacoemulsification training course certification?

5. Self-perceived difficulties $(1=$ Least and $5=$ Most Difficult):

\begin{tabular}{|c|c|c|c|c|c|}
\hline Tasks & \multicolumn{5}{|c|}{ Perceived difficulty levels } \\
\hline \multicolumn{6}{|l|}{ Task-specific indices } \\
\hline Draping: surgical field clear of lashes & 1 & 2 & 3 & 4 & 5 \\
\hline Incision and paracentesis: formation and technique & 1 & 2 & 3 & 4 & 5 \\
\hline Viscoelastic: appropriate use and safe insertion & 1 & 2 & 3 & 4 & 5 \\
\hline Capsulorrhexis: commencement of flap & 1 & 2 & 3 & 4 & 5 \\
\hline Capsulorrhexis: formation and circular completion & 1 & 2 & 3 & 4 & 5 \\
\hline Hydrodissection: visible fluid wave and free nuclear rotation & 1 & 2 & 3 & 4 & 5 \\
\hline Phacoemulsification probe and second instrument: insertion into eye & 1 & 2 & 3 & 4 & 5 \\
\hline $\begin{array}{l}\text { Phacoemulsification probe and second instrument: effective use and stability } \\
\text { within eye }\end{array}$ & 1 & 2 & 3 & 4 & 5 \\
\hline Nucleus: sculpting or primary chop & 1 & 2 & 3 & 4 & 5 \\
\hline Nucleus: rotation and manipulation & 1 & 2 & 3 & 4 & 5 \\
\hline Nucleus: cracking or chopping with safe phacoemulsification of segments & 1 & 2 & 3 & 4 & 5 \\
\hline Irrigation and aspiration technique with adequate removal of cortex & 1 & 2 & 3 & 4 & 5 \\
\hline Lens insertion, rotation, and final position of intraocular lens & 1 & 2 & 3 & 4 & 5 \\
\hline Wound closure (including suturing, hydration, and check security) & 1 & 2 & 3 & 4 & 5 \\
\hline \multicolumn{6}{|l|}{ Global indices } \\
\hline Wound neutrality and minimizing eye rolling and corneal distortion & 1 & 2 & 3 & 4 & 5 \\
\hline Eye positioning centrally within microscope view & 1 & 2 & 3 & 4 & 5 \\
\hline Conjunctival and corneal tissue handling & 1 & 2 & 3 & 4 & 5 \\
\hline Capsule: protection of anterior and posterior capsules & 1 & 2 & 3 & 4 & 5 \\
\hline Iris protection & 1 & 2 & 3 & 4 & 5 \\
\hline Overall speed and fluidity of procedure & 1 & 2 & 3 & 4 & 5 \\
\hline
\end{tabular}

Thank you!

Figure I Survey on ophthalmic residents' perceived difficulties during phacoemulsification cataract extraction surgery.

examination to obtain the Membership of the Royal College of Surgeons of Edinburgh [MRCSEd]), whether they were able to complete phacoemulsification cataract extraction surgery in patients most of the time $(>90 \%)$ without any intervention from their supervisor (Yes or No), and whether they received the certification for the Eyesi phacoemulsification training course (Yes or No).

\section{Statistical analysis}

Mann-Whitney $U$ tests were carried out to compare the means of continuous variables between the subgroups with or without training on Eyesi. Univariate and multivariate regression analyses were performed for potential predictors (higher trainee, can complete phacoemulsification most of the time [90\%] without supervisor's intervention, and certification in the Eyesi training course) and their associations with the tasks in which Eyesi simulation-trained residents had significantly lower difficulty scores. A $P$-value of $<0.05$ was considered to be statistically significant. All of the statistical analyses were performed with SPSS software version 18.0 (SPSS Inc, Chicago, IL, USA).

\section{Results}

There were 22 residents in all five of the regional hospitals, and all were invited to participate in the survey. Nineteen completed the survey, and the response rate was $86.3 \%$. 
The mean \pm SD age of ophthalmic residents who participated in the survey was $28.7 \pm 1.8$ years (range $25-35$ years), of which 11 (57.9\%) were female. Thirteen (68.4\%) had participated and were certified in the Eyesi simulation training course. The mean number of years of training was $3.5 \pm 1.8$ (range $1-5$ years), and 12 (63.2\%) were basic trainees (first year: six trainees; second year: six trainees) and seven (36.8\%) were higher trainees (third year: four trainees; fourth year: two trainees; fifth year: one trainee). Five out of the 19 trainees could complete phacoemulsification in $>90 \%$ of cases without intervention from attending physicians. All five of them were higher trainees.

The mean self-perceived difficulty scores on phacoemulsification procedures of the overall group, the group that did not have Eyesi training, and the group that had Eyesi training are shown in Table 1. Nucleus cracking or chopping was ranked the highest in difficulty by the overall group (mean score $4.06 \pm 0.83$ ). This was followed by capsulorrhexis formation and completion (mean score $3.61 \pm 0.92$ ), nucleus rotation and manipulation (mean score $3.41 \pm 1.28$ ), hydrodissection (mean score $3.22 \pm 1.26$ ), nucleus sculpting or primary chop (mean score $3.12 \pm 1.36$ ), and effective use and stability of phacoemulsification probe and secondary instruments within the eye (mean score 3.12 \pm 1.36 ). For the global indices, overall speed and fluidity of the procedure ranked the highest in difficulty (mean score $3.26 \pm 1.24$ ). Except for hydrodissection and effective use and stability of phacoemulsification probe and secondary instruments within the eye, trainees without prior Eyesi simulation training had significantly higher mean difficulty scores in all the top ranking procedures and global indices. A histogram (Figure 2) illustrates the eight tasks (specific and global) that residents

Table I Mean difficulty scores on 14 specific tasks and six global indices for phacoemulsification based on the International Council of Ophthalmology's Ophthalmology Surgical Competency Assessment Rubric perceived by all respondents $(\mathrm{N}=19)$, the subgroup which had no Eyesi simulation training $(\mathrm{N}=6)$, and the subgroup which had Eyesi simulation training $(\mathrm{N}=13)$

\begin{tabular}{|c|c|c|c|c|c|c|c|}
\hline Task descriptions & $\begin{array}{l}\text { Overall } \\
\text { mean } \pm \text { SD } \\
\text { difficulty } \\
\text { scores }\end{array}$ & Median & $\begin{array}{l}\text { Mean } \pm \text { SD } \\
\text { difficulty } \\
\text { scores } \\
\text { (no Eyesi } \\
\text { training) }\end{array}$ & Median & $\begin{array}{l}\text { Mean } \pm \text { SD } \\
\text { difficulty } \\
\text { scores } \\
\text { (Eyesi } \\
\text { trained) }\end{array}$ & Median & $\begin{array}{l}\text { P-value } \\
\text { (Eyesi vs } \\
\text { no Eyesi) }\end{array}$ \\
\hline \multicolumn{8}{|l|}{ Task-specific indices } \\
\hline I Draping: surgical field clear of lashes & $1.95 \pm 1.268$ & 2.00 & $1.83 \pm 1.602$ & 1.00 & $2 \pm I .155$ & 2.00 & 0.40 \\
\hline 2 Incision and paracentesis: formation and technique & $2.5 \pm 1.295$ & 2.50 & $2.83 \pm 0.753$ & 3.00 & $2.33 \pm 1.497$ & 2.00 & 0.27 \\
\hline 3 Viscoelastic: appropriate use and safe insertion & $1.95 \pm 1.026$ & 2.00 & $2.5 \pm 0.548$ & 2.50 & $1.69 \pm 1.109$ & 1.00 & 0.02 \\
\hline 4 Capsulorrhexis: commencement of flap & $2.83 \pm 1.425$ & 3.00 & $4 \pm 1.225$ & 4.00 & $2.38 \pm 1.26 \mid$ & 2.00 & 0.04 \\
\hline 5 Capsulorrhexis: formation and circular completion & $3.61 \pm 0.916$ & 4.00 & $4.4 \pm 0.548$ & 4.00 & $3.31 \pm 0.855$ & 3.00 & 0.02 \\
\hline 6 Hydrodissection: visible fluid wave and free nuclear rotation & $3.22 \pm 1.263$ & 3.00 & $3.8 \pm 1.095$ & 3.00 & $3.0 \pm 1.291$ & 3.00 & 0.29 \\
\hline $\begin{array}{l}7 \text { Phacoemulsification probe and second instrument: insertion } \\
\text { into eye }\end{array}$ & $2.1 I \pm I .4 I$ & 2.00 & $2.8 \pm 1.643$ & 2.00 & $1.85 \pm 1.281$ & 1.00 & 0.17 \\
\hline $\begin{array}{l}8 \text { Phacoemulsification probe and second instrument: effective } \\
\text { use and stability within eye }\end{array}$ & $3.12 \pm 1.364$ & 3.00 & $3.5 \pm 1.291$ & 4.00 & $2.83 \pm 1.115$ & 3.00 & 0.35 \\
\hline 9 Nucleus: sculpting or primary chop & $3.12 \pm 1.364$ & 3.00 & $4.5 \pm 1$ & 5.00 & $2.69 \pm 1.182$ & 3.00 & 0.02 \\
\hline I0 Nucleus: rotation and manipulation & $3.4 I \pm 1.278$ & 4.00 & $4.75 \pm 0.5$ & 5.00 & $3 \pm I .155$ & 3.00 & 0.01 \\
\hline $\begin{array}{l}\text { I I Nucleus: cracking or chopping with safe phacoemulsification } \\
\text { of segments }\end{array}$ & $4.06 \pm 0.827$ & 4.00 & $4.75 \pm 0.5$ & 5.00 & $3.85 \pm 0.801$ & 4.00 & 0.03 \\
\hline $\begin{array}{l}\text { I2 Irrigation and aspiration technique with adequate removal of } \\
\text { cortex }\end{array}$ & $2.76 \pm 1.251$ & 2.00 & $3.75 \pm 0.957$ & 3.50 & $2.46 \pm 1.198$ & 2.00 & 0.05 \\
\hline I3 Lens insertion, rotation, and final position of intraocular lens & $2.37 \pm 1.065$ & 2.00 & $3.17 \pm 0.408$ & 3.00 & $2 \pm 1.08$ & 2.00 & 0.01 \\
\hline $\begin{array}{l}\text { I4 Wound closure (including suturing, hydration, and } \\
\text { check security) }\end{array}$ & $2.05 \pm 0.97$ & 2.00 & $2.33 \pm 0.816$ & 2.50 & $1.92 \pm 1.038$ & 2.00 & 0.15 \\
\hline \multicolumn{8}{|l|}{ Global indices } \\
\hline $\begin{array}{l}\text { Wound neutrality and minimizing eye rolling and } \\
\text { corneal distortion }\end{array}$ & $2.05 \pm 0.97$ & 3.00 & $2.83 \pm 0.753$ & 3.00 & $2.83 \pm 1.193$ & 3.00 & 0.96 \\
\hline 2 Eye positioning centrally within microscope view & $2.16 \pm 1.119$ & 2.00 & $1.83 \pm 0.753$ & 2.00 & $2.31 \pm 1.25 I$ & 2.00 & 0.49 \\
\hline 3 Conjunctival and corneal tissue handling & $2.53 \pm 0.964$ & 3.00 & $2.83 \pm 0.408$ & 3.00 & $2.38 \pm 1.121$ & 2.00 & 0.20 \\
\hline 4 Capsule: protection of anterior and posterior capsules & $3 \pm 1$ & 3.00 & $3.17 \pm 0.753$ & 3.00 & $2.92 \pm 1.188$ & 3.00 & 0.70 \\
\hline 5 Iris protection & $2.89 \pm 1.049$ & 3.00 & $3.17 \pm 0.753$ & 3.00 & $2.77 \pm 1.166$ & 3.00 & 0.41 \\
\hline 6 Overall speed and fluidity of procedure & $3.26 \pm 1.24$ & 3.00 & $4.33 \pm 0.816$ & 4.50 & $2.77 \pm 1.092$ & 3.00 & 0.01 \\
\hline
\end{tabular}

Note: Statistically significant values are shown in bold $(P<0.05)$. 


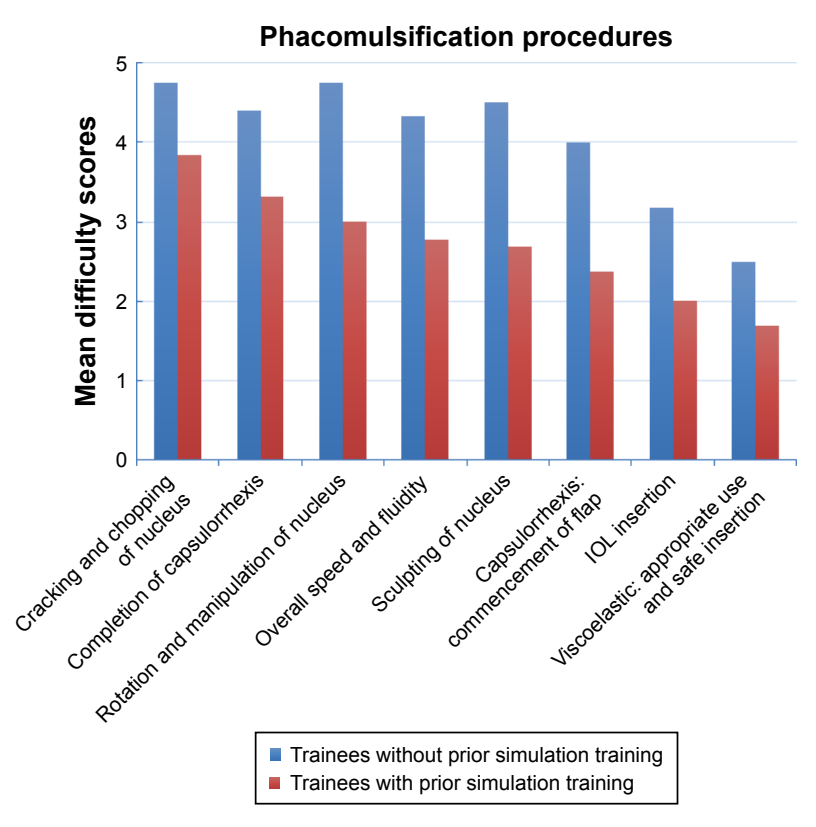

Figure 2 Histogram of mean difficulty scores of the eight tasks that trainees without Eyesi training had significantly higher scores than trainees who had the Eyesi training. These tasks were ordered from left to right on the histogram according to the highest difficulty ranking perceived by the overall group to the least difficult.

Abbreviation: IOL, intraocular lens.

without Eyesi training had significantly higher mean difficulty scores than those who had Eyesi training. These tasks were ordered from left to right on the histogram according to the highest difficulty ranking perceived by the overall group to the least difficult.

Regression analyses were performed to evaluate the associations of the eight tasks that the residents with Eyesi simulation training had significantly lower mean difficulty scores (Tables 2 and 3 ) with potential predictors. In univariate analyses, higher trainees were significantly associated with lower difficulty scores in overall speed and fluidity of procedure, commencement of capsulorrhexis flap, intraocular lens (IOL) insertion, and appropriate use and safe insertion of viscoelastic. Residents who could complete phacoemulsification most of the time ( $>90 \%$ ) without supervisor's intervention were significantly associated with lower difficulty score in commencement of capsulorrhexis flap. In multivariate analyses, residents who were certified in the Eyesi simulation course were significantly associated with lower difficulty scores in cracking and chopping of lens nucleus, completion of capsulorrhexis, rotation and manipulation of lens nucleus, and sculpting or primary chopping of nucleus.

\section{Discussion}

In this study, we have identified the top learning barriers to phacoemulsification cataract extraction surgery perceived by ophthalmic residents in Hong Kong. We expected that higher trainees, and trainees who were able to complete phacoemulsification most of the time without needing attending physician intervention, would also have the lowest difficulty scores in the surgical tasks. ${ }^{26}$ However, after adjusting for these two potential confounding factors, Eyesi simulation training was significantly associated with increased confidence in higher difficulty surgical tasks. Virtual reality simulation training on the validated Eyesi modules followed by proficiency assessment appeared to be effective in lowering the perceived difficulties in performing the most skills-demanding phacoemulsification procedures on actual patients as rated by the residents.

Our survey was designed according to the ICO-OSCAR tool. ${ }^{25}$ The rubric draft was developed by content experts from around the world based on the Dreyfus model of skill acquisition and revised by expert panels in teaching cataract surgery. ${ }^{27}$ Hence, the respondents were able to gain thorough understandings on how their surgical proficiencies on actual patients would be assessed objectively based on the ICO-OSCAR before ranking the difficulty levels on the survey. Previous surveys on self-perceived training difficulties in phacoemulsification cataract extraction surgery did not use a standardized format to describe the specific surgical tasks. ${ }^{28,29}$ In 2006, Dooley and O'Brien reported the surgical procedures that were perceived to be most difficult by eight trainees during phacoemulsification cataract extraction surgery were 1) phacoemulsification, 2) capsulorrhexis, 3) irrigation/aspiration (I/A), 4) IOL insertion, and 5) hydrodissection. ${ }^{28}$ Prakash et al reported in 2009 that 36 trainees ranked 1) foldable IOL insertion as the most difficult task, followed by 2) nucleus emulsification, 3) I/A, 4) capsulorrhexis, and 5) hydrodelineation. ${ }^{29}$ Our questionnaire, based on the ICO-OSCAR guideline, had dissected the specific steps required to accomplish phacoemulsification of the nucleus, and we have identified that cracking and chopping, rotation and manipulation, and sculpting of the nucleus were among the most difficult tasks perceived by residents. Our survey provided important and updated information on the perceived learning barriers by ophthalmic residents in phacoemulsification, which could have changed from the previous decade because of the availability of improved fluidics and followability of advanced phacoemulsification systems, and newer inserters for rolled IOL through small corneal incisions. ${ }^{30}$

Nevertheless, the development of user-friendly phacoemulsification systems has not changed the skills demanded from the surgeon when performing capsulorrhexis, other than the availability of femtosecond laser assistance which has not yet been implemented in public hospitals in Hong Kong. 

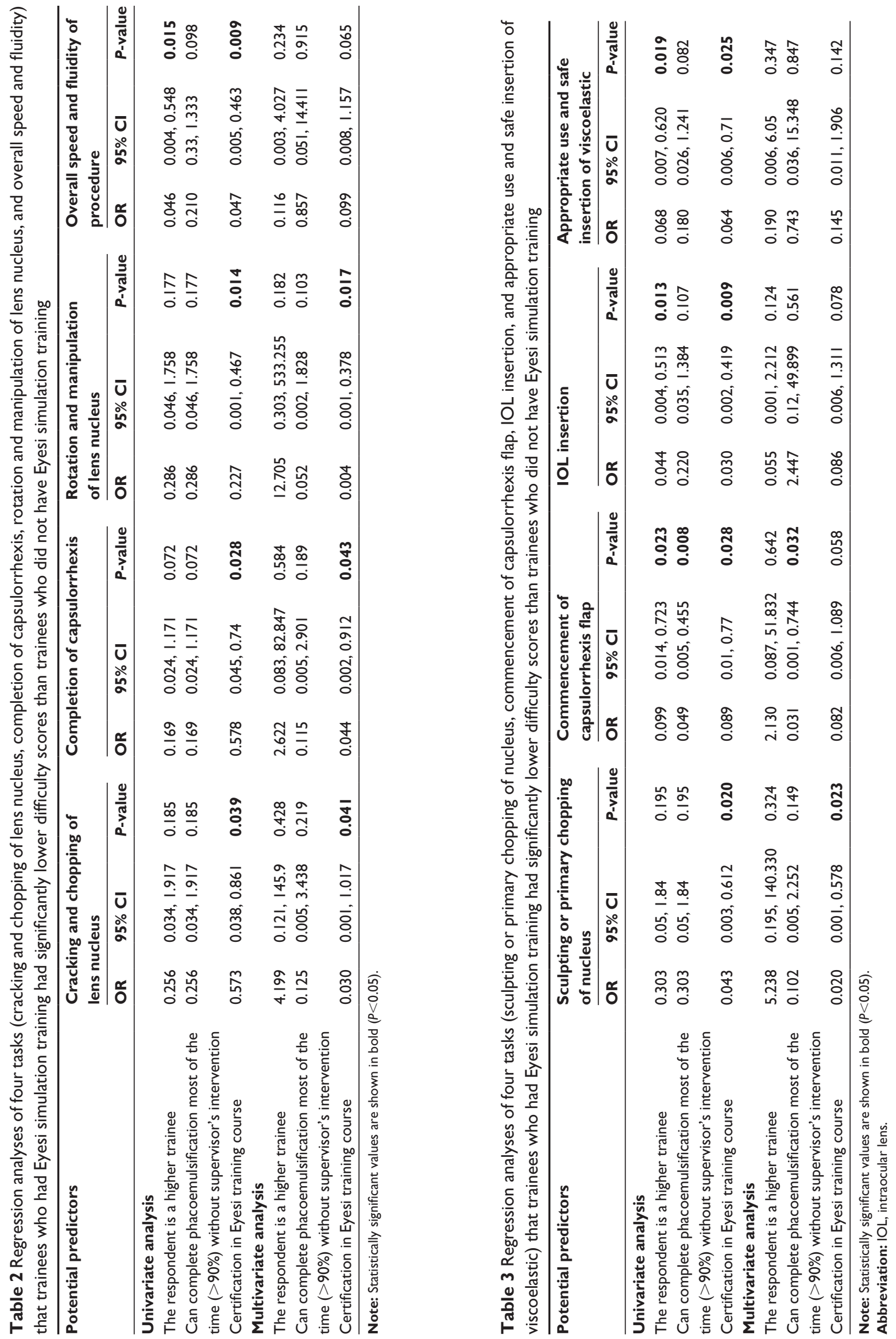
Capsulorrhexis had been regarded as one of the most challenging procedures during phacoemulsification cataract extraction surgery in this study as well as in a number of previous studies..$^{26,28,29,31}$ When capsulorrhexis is attempted, there is a natural tendency for the flap to extend radially which increases the subsequent risk of posterior capsule tear resulting in vitreous loss and lens nucleus drop. Thus, it is considered crucial for residents to master the skills in performing capsulorrhexis to minimize the rates of cataract surgery complications. Because capsulorrhexis and lens nucleus cracking and chopping are among the initial steps of phacoemulsification cataract extraction surgery which have a steep learning curve, some attending physicians would prefer to teach phacoemulsification starting from reverse order: the trainee surgeon performs I/A and IOL insertion after the supervisor completes capsulorrhexis and phacoemulsification of the lens. ${ }^{28,32,33}$ This reverse teaching approach could deprive the chances of novice surgeons to practice performing the tasks that have the steepest learning curves, but this approach is better for patient care and safety.

The paradox of traditional apprenticeship-based surgical training is that today's patients can be harmed in the training of tomorrow's surgeons. Moreover, the patient can be an unforgiving teacher. The trainees are exposed to real-time pressures during surgery on actual patients, especially when the majority of cataract extraction surgeries are performed under local anesthesia. The rate of posterior capsule tear among trainee surgeons has been shown to vary from $4.8 \%$ to $15 \% .{ }^{10-16}$ Experienced surgeons tend to have much lower complication rates, with a vitreous loss rate of $0.53 \%-1.63 \%{ }^{34-36}$ Simulation surgical training allows the trainees to experience the consequences of their decisions and actions as they learn new skills without putting patients at risk. The construct validity of a number of training modules on the Eyesi simulator has been reported. ${ }^{19-23,37}$ Saleh et al evaluated the repeatability and reproducibility of the capsulorrhexis, nucleus cracking and chopping, navigation, bimanual training, and anti-tremor modules in 18 residents. ${ }^{37}$ Mahr and Hodge showed construct validity of anterior segment anti-tremor and forceps training modules in 15 participants comprising residents and experienced surgeons, and the experienced surgeons showed statistically significant better scores and faster time to complete the designated tasks. ${ }^{19}$

Our simulation course was implemented based on a training program that had been established by the International Forum of Ophthalmic Simulation (IFOS) using the Eyesi simulator. ${ }^{24}$ Saleh et al compared the entry and exit proficiency scores of 16 novice eye surgeons in performing the four validated modules (navigation, anti-tremor, capsulorrhexis, and nucleus cracking and chopping training) and showed a significant improvement for all these tasks in addition to the overall scores. ${ }^{24}$ Our survey found that the proficiencybased Eyesi simulation course had boosted the confidence of ophthalmic residents in performing the most difficult tasks in phacoemulsification, regardless of their training status and prior experience in cataract surgery on actual patients. Our simulation course did not have an impact on the residents' confidence in performing hydrodissection and effective use and stability of phacoemulsification probe and secondary instruments within the eye, which highlights the necessity of utilizing and assessing the effect of the hydrodissection/ hydrodelineation and instruments insertion/removal training modules on Eyesi in the future.

The encouraging results of our survey lay the foundation for future research to evaluate the efficacy of virtual reality simulation phacoemulsification training on patient-related outcomes. Three retrospective studies had reported improved outcomes in the operating theatre associated with Eyesi simulation training. ${ }^{38-40}$ Belyea et al reported a significant decrease in phacoemulsification time and power use $(2.4$ vs 1.9 minutes, $P<0.002 ; 28.2 \%$ vs $25.3 \%, P<0.0001$, respectively) following training on Eyesi. ${ }^{39}$ Baxter et al found that the complication rates of cataract surgeries performed by resident trainees who had Eyesi training were lower than those previously reported in the literature..$^{40,41} \mathrm{McC}$ annel et al found a significant decrease in the number of errant continuous curvilinear capsulorrhexes during cataract surgery after a capsulorrhexis-intensive training curriculum on the Eyesi simulator $(15.7 \%$ vs $5.0 \%$ in the postintervention cohort; $P<0.0001) .{ }^{38}$ Two prospective studies have been performed. ${ }^{41,42}$ Pokroy et al found significant decrease in operation time but nonsignificant difference in complication rates before and after training with Eyesi. ${ }^{41}$ Recently, Thomsen et al reported that Objective Structured Assessment of Cataract Surgical Skill (OSACSS) scores when performing phacoemulsification on actual patients significantly improved by $32 \%$ in novice surgeons and $38 \%$ in intermediatelevel surgeons who performed $>75$ surgeries even after adjusted for the effect of learning curve in a prospective, cohort study. ${ }^{42}$

Our study was limited by lack of evaluation of patientrelated outcomes associated with Eyesi simulation training and small sample size. We did not use other simulation modalities, such as porcine eyes, MicroVisTouch (ImmersiveTouch, Chicago, IL, USA), and PhacoVision (Melerit Medical, Linkoping, Sweden), for comparison with the Eyesi 
platform. Hence, we cannot ascertain whether any one of these simulation tools were just as effective as Eyesi in surgical training of novice surgeons at the initial stages of their learning curves. We reported subjective rankings perceived by the trainees without self-evaluations on surgical videos or objective rankings by experienced attending physicians. Using the OSACSS, Casswell et al studied the agreement between trainees and their evaluators in grading their own performances in surgical tasks during phacoemulsification on actual patients and found that senior trainees were more able to assess their performance than junior trainees, supporting the notion that trainees progress from being relatively unconsciously incompetent to becoming consciously competent during their surgical training. ${ }^{43}$

\section{Conclusion}

Our study identified the updated perceptions on training barriers from ophthalmic residents. The responses of our survey reflected that ophthalmic residents were satisfied with the outcome of a structured Eyesi training course using validated training modules followed by a proficiency test. Our study has demonstrated level 1 evidence of the Kirkpatrick model in the evaluation of educational intervention. ${ }^{44}$ The efficacy of virtual reality simulation cataract surgery training has only been proven to a certain extent. ${ }^{45}$ Current evidence and assessment of simulator-based training is characterized by a scattered focus and lack of rigorous methodologies to ensure effective skills transfer to the operation theatre. ${ }^{45}$ The ultimate goal of simulator use is to improve patient safety and outcomes by trainees. Given the wide adoption of simulator-based training by universities and tertiary ophthalmic centers in many parts of the world, there is an imminent need for a robust clinical trial to justify the efficacy of implementing virtual reality simulator training modules in structured phacoemulsification surgery training programs.

\section{Disclosure}

The authors report no conflicts of interest in this work.

\section{References}

1. Bourne RR, Stevens GA, White RA, et al. Causes of vision loss worldwide, 1990-2010: a systematic analysis. Lancet Glob Health. 2013; 1(6): e339-e349.

2. Pascolini D, Mariotti SP. Global estimates of visual impairment: 2010. Br J Ophthalmol. 2012;96(5):614-618.

3. Michon JJ, Lau J, Chan WS, Ellwein LB. Prevalence of visual impairment, blindness, and cataract surgery in the Hong Kong elderly. $\mathrm{Br} J$ Ophthalmol. 2002;86(2):133-139.

4. Wong TY, Zheng Y, Jonas JB, et al. Prevalence and causes of vision loss in East Asia: 1990-2010. Br J Ophthalmol. 2014;98(5):599-604.
5. Waiting time for cataract surgery [webpage on the Internet]. Hong Kong: Hospital Authority; 2018 [updated December 31, 2016]. Available from: https://www.ha.org.hk/visitor/ha_visitor_text_index. asp?Parent_ID=214172\&Content_ID=214184. Accessed January 14, 2017.

6. Grillo HC, Edward D. Churchill and the "rectangular" surgical residency. Surgery. 2004;136(5):947-952.

7. Randleman JB, Wolfe JD, Woodward M, Lynn MJ, Cherwek DH, Srivastava SK. The resident surgeon phacoemulsification learning curve. Arch Ophthalmol. 2007;125(9):1215-1219.

8. Randleman JB, Srivastava SK, Aaron MM. Phacoemulsification with topical anesthesia performed by resident surgeons. J Cataract Refract Surg. 2004;30(1):149-154.

9. Badoza DA, Jure T, Zunino LA, Argento CJ. State-of-the-art phacoemulsification performed by residents in Buenos Aires, Argentina. J Cataract Refract Surg. 1999;25(12):1651-1655.

10. Rutar T, Porco TC, Naseri A. Risk factors for intraoperative complications in resident-performed phacoemulsification surgery. Ophthalmology. 2009;116(3):431-436.

11. Hashemi H, Mohammadpour M, Jabbarvand M, Nezamdoost Z, Ghadimi H. Incidence of and risk factors for vitreous loss in residentperformed phacoemulsification surgery. J Cataract Refract Surg. 2013; 39(9):1377-1382.

12. Lee JS, Hou CH, Yang ML, Kuo JZ, Lin KK. A different approach to assess resident phacoemulsification learning curve: analysis of both completion and complication rates. Eye. 2009;23(3):683-687.

13. Tayanithi P, Pungpapong K, Siramput P. Vitreous loss during phacoemulsification learning curve performed by third-year residents. J Med Assoc Thai. 2005;88 Suppl 9:S89-S93.

14. Singh A, Stewart JM. Phacoemulsification performed by residents. $J$ Cataract Refract Surg. 2007;33(5):755; author reply 755-756.

15. Lomi N, Sharma R, Khokhar S, Dada T, Vanathi M, Agarwal T. Risk factors for intra-operative complications during phacoemulsification performed by residents. Int Ophthalmol. 2016;36(3):401-406.

16. Feldman BH, Geist CE. Assessing residents in phacoemulsification. Ophthalmology. 2007;114(8):1586.

17. Taravella MJ, Davidson R, Erlanger M, Guiton G, Gregory D. Time and cost of teaching cataract surgery. J Cataract Refract Surg. 2014;40(2): 212-216.

18. Hosler MR, Scott IU, Kunselman AR, Wolford KR, Oltra EZ, Murray WB. Impact of resident participation in cataract surgery on operative time and cost. Ophthalmology. 2012;119(1):95-98.

19. Mahr MA, Hodge DO. Construct validity of anterior segment antitremor and forceps surgical simulator training modules: attending versus resident surgeon performance. J Cataract Refract Surg. 2008;34(6): 980-985.

20. Privett B, Greenlee E, Rogers G, Oetting TA. Construct validity of a surgical simulator as a valid model for capsulorhexis training. J Cataract Refract Surg. 2010;36(11):1835-1838.

21. Le TD, Adatia FA, Lam WC. Virtual reality ophthalmic surgical simulation as a feasible training and assessment tool: results of a multicentre study. Can J Ophthalmol. 2011;46(1):56-60.

22. Nathoo N, Ng M, Ramstead CL, Johnson MC. Comparing performance of junior and senior ophthalmology residents on an intraocular surgical simulator. Can J Ophthalmol. 2011;46(1):87-88.

23. Selvander M, Asman P. Virtual reality cataract surgery training: learning curves and concurrent validity. Acta Ophthalmol. 2012;90(5): 412-417.

24. Saleh GM, Lamparter J, Sullivan PM, et al. The International Forum of Ophthalmic Simulation: developing a virtual reality training curriculum for ophthalmology. Br J Ophthalmol. 2013;97(6):789-792.

25. Saleh GM, Gauba V, Mitra A, Litwin AS, Chung AK, Benjamin L. Objective structured assessment of cataract surgical skill. Arch Ophthalmol. 2007;125(3):363-366.

26. Taravella MJ, Davidson R, Erlanger M, Guiton G, Gregory D. Characterizing the learning curve in phacoemulsification. $J$ Cataract Refract Surg. 2011;37(6):1069-1075. 
27. Golnik KC, Haripriya A, Beaver H, et al. Cataract surgery skill assessment. Ophthalmology. 2011;118(10):2094-2094.e2.

28. Dooley IJ, O'Brien PD. Subjective difficulty of each stage of phacoemulsification cataract surgery performed by basic surgical trainees. $J$ Cataract Refract Surg. 2006;32(4):604-608.

29. Prakash G, Jhanji V, Sharma N, Gupta K, Titiyal JS, Vajpayee RB. Assessment of perceived difficulties by residents in performing routine steps in phacoemulsification surgery and in managing complications. Can J Ophthalmol. 2009;44(3):284-287.

30. Christakis PG, Braga-Mele RM. Intraoperative performance and postoperative outcome comparison of longitudinal, torsional, and transversal phacoemulsification machines. J Cataract Refract Surg. 2012;38(2):234-241.

31. Woodfield AS, Gower EW, Cassard SD, Ramanthan S. Intraoperative phacoemulsification complication rates of second- and third-year ophthalmology residents: a 5-year comparison. Ophthalmology. 2011; 118(5):954-958.

32. Suryawanshi M, Gogate P, Kulkarni AN, Biradar A, Bhomaj P. Comparison of the posterior capsule rupture rates associated with conventional (start to finish) versus reverse methods of teaching phacoemulsification. Middle East Afr J Ophthalmol. 2016;23(2):163-167.

33. Fischer AF, PiresEM, KleinF, Siqueira Bisneto O, Soriano ES, Moreira H. Programa de ensino de facoemulsificação CBO/ALCON: resultados do Hospital de Olhos do Paraná [CBO/ALCON teaching method of phacoemulsification: results of Hospital de Olhos do Paraná]. Arq Bras Oftalmol. 2010;73(6):517-520. Portuguese.

34. Narendran N, Jaycock P, Johnston RL, et al. The Cataract National Dataset electronic multicentre audit of 55,567 operations: risk stratification for posterior capsule rupture and vitreous loss. Eye. 2009; 23(1):31-37.

35. Bell CM, Hatch WV, Cernat G, Urbach DR. Surgeon volumes and selected patient outcomes in cataract surgery: a population-based analysis. Ophthalmology. 2007;114(3):405-410.
36. Misra A, Burton RL. Incidence of intraoperative complications during phacoemulsification in vitrectomized and nonvitrectomized eyes: prospective study. J Cataract Refract Surg. 2005;31(5):1011-1014.

37. Saleh GM, Theodoraki K, Gillan S, et al. The development of a virtual reality training programme for ophthalmology: repeatability and reproducibility (part of the International Forum for Ophthalmic Simulation Studies). Eye. 2013;27(11):1269-1274.

38. McCannel CA, Reed DC, Goldman DR. Ophthalmic surgery simulator training improves resident performance of capsulorhexis in the operating room. Ophthalmology. 2013;120(12):2456-2461.

39. Belyea DA, Brown SE, Rajjoub LZ. Influence of surgery simulator training on ophthalmology resident phacoemulsification performance. $J$ Cataract Refract Surg. 2011;37(10):1756-1761.

40. Baxter JM, Lee R, Sharp JA, Foss AJ; Intensive Cataract Training Study G. Intensive cataract training: a novel approach. Eye. 2013;27(6): $742-746$.

41. Pokroy R, Du E, Alzaga A, et al. Impact of simulator training on resident cataract surgery. Graefes Arch Clin Exp Ophthalmol. 2013;251(3): $777-781$.

42. Thomsen AS, Bach-Holm D, Kjaerbo H, et al. Operating room performance improves after proficiency-based virtual reality cataract surgery training. Ophthalmology. 2017;124(4):524-531.

43. Casswell EJ, Salam T, Sullivan PM, Ezra DG. Ophthalmology trainees' self-assessment of cataract surgery. Br J Ophthalmol. 2016;100(6): 766-771.

44. Harden RM, Grant J, Buckley G, Hart IR. BEME guide no. 1: best evidence medical education. Med Teach. 1999;21(6):553-562.

45. Thomsen AS, Subhi Y, Kiilgaard JF, la Cour M, Konge L. Update on simulation-based surgical training and assessment in ophthalmology: a systematic review. Ophthalmology. 2015;122(6):1111-1130.e1.
Clinical Ophthalmology

\section{Publish your work in this journal}

Clinical Ophthalmology is an international, peer-reviewed journal covering all subspecialties within ophthalmology. Key topics include: Optometry; Visual science; Pharmacology and drug therapy in eye diseases; Basic Sciences; Primary and Secondary eye care; Patient Safety and Quality of Care Improvements. This journal is indexed on

\section{Dovepress}

PubMed Central and CAS, and is the official journal of The Society of Clinical Ophthalmology (SCO). The manuscript management system is completely online and includes a very quick and fair peer-review system, which is all easy to use. Visit http://www.dovepress.com/ testimonials.php to read real quotes from published authors. 